\title{
A novel application for energy efficiency improvement using nanofluid in shell and tube heat exchanger equipped with helical baffles
}

\author{
Mehdi Bahiraei $^{1, *}$, Morteza Hangi ${ }^{2}$, Mahdi Saeedan ${ }^{3}$ \\ ${ }^{1}$ Mechanical Engineering Department, School of Energy, Kermanshah University of Technology, Kermanshah, Iran \\ ${ }^{2}$ Research School of Engineering, The Australian National University, Canberra, ACT 2601, Australia \\ ${ }^{3}$ Mechanical Engineering Department, Faculty of Engineering, University of Isfahan, Isfahan, Iran
}

Corresponding author: Mehdi Bahiraei

* E-mail: m.bahiraei@kut.ac.ir

Tel: +988337259980

\begin{abstract}
Hydrothermal characteristics of the water- $\mathrm{Al}_{2} \mathrm{O}_{3}$ nanofluid are numerically evaluated in shelland-tube heat exchanger equipped with helical baffles using the two-phase mixture model. Heat transfer and pressure drop increase by increasing nanoparticle concentration and baffle overlapping, and decreasing helix angle. At smaller helix angles, changing the overlapping is more effective on the convective heat transfer coefficient and the pressure drop. Neural network is used for modeling, and based on the test data, the model predicts the convective heat transfer coefficient and the pressure drop with MRE values of about $0.089 \%$ and $0.65 \%$, respectively. In order to obtain conditions of effective parameters which cause maximum heat transfer along with minimum pressure drop, optimization is performed on the neural network model using both two-
\end{abstract}


objective and single-objective approaches. 15 optimal states obtain from two-objective optimization. The results obtained from single-objective optimization indicate that even when a low pressure drop is significantly important for designer, nanofluids with high concentrations can be employed. Meanwhile, when both high heat transfer and low pressure drop are important, a small helix angle can be used. In addition, using large overlapping is recommended only when the heat transfer enhancement is considerably more important than the reduction of the pressure drop.

Keywords: Nanofluid, two-phase mixture model, heat exchanger, helical baffles, optimization

\begin{tabular}{|c|c|c|c|}
\hline \multicolumn{2}{|c|}{ Nomenclature } & \multirow{2}{*}{$\begin{array}{l}\mathbf{v} \\
V_{B}\end{array}$} & \multirow{2}{*}{$\begin{array}{l}\text { velocity, } \mathrm{m} / \mathrm{s} \\
\text { Brownian velocity, m/s }\end{array}$} \\
\hline$A$ & area, $m^{2}$ & & \\
\hline$a$ & acceleration, $\mathrm{m} / \mathrm{s}^{2}$ & $v_{d r, p}$ & drift velocity, $\mathrm{m} / \mathrm{s}$ \\
\hline$b$ & distance parameter & $v_{p f}$ & relative velocity, m/s \\
\hline$C_{c}$ & Cunningham correction factor & $W$ & objective function \\
\hline$C_{p}$ & specific heat, $J / \mathrm{kgK}$ & $Z$ & objective function \\
\hline$D$ & internal diameter of the shell, $\mathrm{m}$ & \multicolumn{2}{|c|}{ Greek symbols } \\
\hline$D_{2}$ & objective function of compromise programming & $\alpha$ & weight coefficients of objective functions \\
\hline$d$ & diameter of tubes, $m$ & $\beta$ & helix angle, degree \\
\hline$d_{p}$ & diameter of nanoparticle, $\mathrm{m}$ & $\gamma$ & performance ratio \\
\hline$e_{i}$ & error for each pattern & $\delta$ & distance between the particles, $\mathrm{m}$ \\
\hline$h$ & convective heat transfer coefficient, $W / \mathrm{m}^{2} K$ & $\lambda$ & mean free path, $\mathrm{m}$ \\
\hline$k$ & thermal conductivity, $W / m K$ & $\mu$ & dynamic viscosity, Pa.s \\
\hline$k_{B}$ & Boltzman constant, J/K & $\rho$ & density, $\mathrm{kg} / \mathrm{m}^{3}$ \\
\hline$\dot{m}$ & mass flow rate, $\mathrm{kg} / \mathrm{s}$ & $\varphi$ & volume concentration \\
\hline$n$ & number of tubes & Sub & \\
\hline
\end{tabular}




\begin{tabular}{|llll|}
\hline$P$ & pressure, $\mathrm{Pa}$ & $f$ & base fluid \\
$p$ & baffle pitch, $\mathrm{m}$ & in & inlet \\
$Q$ & heat exchange quantity, $W$ & $m$ & mixture \\
$r$ & radial coordinate & out & outlet \\
$S$ & overlapping & $p$ & particle \\
$T$ & temperature, $\mathrm{K}$ & & \\
\hline
\end{tabular}

\section{Introduction}

Heat transfer via fluid flow plays a pivotal role in various industries such as power plants, refineries, electronics, and so forth. Regarding recent technological advancements in industries, numerous studies have been conducted thus far in order to find different methods for heat transfer enhancement [1-4].

One of the major limitations on different methods of enhancement in heat transfer by means of fluid flow is the inherently poor thermal properties of conventional heat transfer fluids such as water and ethylene glycol in comparison with solids. Recent furtherance in the field of nanotechnology paved the way for production of solid nano-sized particles, which led to the introduction of the novel suspensions containing such particles, known as nanofluids, by Choi [5] to improve thermal properties of fluids.

Due to the size effect and Brownian motion of the nanoparticles in the base fluid, nanofluids exhibit proper stability compared to conventional suspensions with micro- or milli-sized solid particles. In addition, numerous studies have been carried out to improve the stability of nanofluids and to prevent two phenomena which are critical to the stability of nanofluid, i.e. aggregation and sedimentation [6,7]. Having this in mind, nanofluids have attracted the attention of many researchers, particularly in the field of thermal engineering [8-10]. 
Among the numerous investigations carried out thus far, several numerical studies have been implemented on nanofluids based on two general approaches, namely: single-phase and twophase. The former assumes that the fluid phase and particles are in hydrothermal equilibrium, while the latter provides the possibility of understanding the interaction between the fluid phase and solid particles in the flow and heat transfer process. In single-phase approach, which is simpler and requires less computational time, the effective properties of nanofluids are taken into account to solve the conservation equations and most studies have benefitted from this approach to numerically simulate the flow and heat transfer of nanofluids [11-13]. However, due to several factors such as gravity, friction between the fluid and solid particles, Brownian force, sedimentation and so forth, not considering the interaction between the base fluid and nanoparticles can lead to error in numerical simulation. Therefore, as demonstrated by Haghshenas Fard et al. [14], two-phase approaches can better model nanofluids behavior. In addition, the numerical and experimental results of the study conducted by Bahiraei and Hosseinalipour [15] using the two-phase Euler-Lagrange method, and Naphon and Nakharintr [16] using the two-phase mixture model indicated that these methods present results very close to those of experiments. Just a limited number of studies have been launched using two-phase methods. Bahremand et al. [17] analyzed the turbulent flow of water-silver nanofluid in helically coiled tubes under constant wall heat flux. They applied the two-phase Euler-Lagrange approach along with an RNG $k-\varepsilon$ turbulence model accounting for four-way coupling collisions. It was observed that the two-phase approach predicts the results much more accurately in comparison with the homogeneous model. Narrein et al. [18] performed a three-dimensional numerical simulation using the two-phase mixture model with modified effective thermal conductivity and viscosity equations to investigate nanofluid flow in a helical microchannel heat sink. It was 
stated that such numerical analysis provides a unique fundamental insight into the complex secondary flow pattern in the channel due to curvature effects.

A review on the existing literature indicates that most studies in the field of heat transfer enhancement using nanofluids have been conducted in simple geometries such as circular tubes, annuli and straight channels. However, the thermal systems which are used in industries, such as various types of heat exchangers, are far more complicated than the above mentioned geometries. Very few studies have assessed the effect of using nanofluids in different heat exchangers. Khoshvaght-Aliabadi [19] experimentally assessed the effects of vortex-generator (VG) and Cu-water nanofluid flow on the performance of plate-fin heat exchangers. It was observed that utilizing the VG channel instead of the plain channel remarkably enhances the heat transfer rate. In addition, it was concluded that application of VG is more effective than the using nanofluid on the performance of plate-fin heat exchangers, and the combination of the two heat transfer enhancement techniques has a noticeably high hydrothermal performance. Durga Prasad et al. [20] performed an experimental study to analyze on the heat transfer performance of nanofluid in a double pipe U-bend heat exchanger. Two methods of heat transfer augmentation were considered, i.e. active method by providing a bend in the test tube, and passive method using nanofluid as well as helical tape inserts. In the active method, about 5\% heat transfer enhancement was observed for water flowing in a heat exchanger at $\operatorname{Re}=30000$, while the enhancement was $8.7 \%$ for the case of using nanofluid with $3 \%$ concentration.

Shell-and-Tube Heat Exchangers (STHXs) are one of the mostly used types of heat exchangers in industry. Some studies have been conducted so far to investigate the effect of using nanofluids in such heat exchangers [21-28]. Shahrul et al. [29] investigated thermal performance of a STHX operated with nanofluids flowing in the tube-side at different mass flow rates. Different 
nanoparticles suspended in water at 0.03 volume fractions were considered. It is found that, for a certain mass flow rate of tube-side and shell-side fluid, the highest heat transfer coefficient belongs to $\mathrm{Al}_{2} \mathrm{O}_{3}$-water nanofluid and the lowest to $\mathrm{CuO}$-water nanofluid. However, maximum energy effectiveness improvement took place by $43 \%$ for $\mathrm{ZnO}$-water nanofluid, while the minimum improvement of $31 \%$ happened for $\mathrm{Al}_{2} \mathrm{O}_{3}$-water nanofluid. Farajollahi et al. [30] investigated the effects of Peclet number, nanoparticles concentration and particle type on heat transfer characteristics of $\gamma-\mathrm{Al}_{2} \mathrm{O}_{3}$-water and $\mathrm{TiO}_{2}$-water nanofluids in a STHX. The experimental results indicated that for a given Peclet number, heat transfer characteristics of $\mathrm{TiO}_{2}$-water nanofluid at its optimum nanoparticle concentration are greater than those of $\gamma$ $\mathrm{Al}_{2} \mathrm{O}_{3}$-water nanofluid, while $\gamma-\mathrm{Al}_{2} \mathrm{O}_{3}$-water nanofluid possesses better heat transfer behavior at higher nanoparticle concentrations. Bahiraei et al. [31] investigated heat transfer and flow field of water- $\mathrm{Al}_{2} \mathrm{O}_{3}$ nanofluid in the shell-side of a STHX with helical baffles. The effects of Reynolds number and volume fraction on heat transfer and pressure drop were assessed. The results showed that increasing the volume fraction and Reynolds number intensifies both heat transfer and pressure drop. Moreover, reduction of the Reynolds number increased the friction factor, but no considerable change was observed in the friction factor by increasing the volume fraction at a constant Reynolds number. In this study, the authors applied the single-phase approach in the simulation. In addition, the investigation was carried out at constant geometrical parameters (i.e. constant overlapping and helix angle).

Baffles are key shell-side components of STHXs which conduct the shell-side flow perpendicular to the tubes in addition to supporting the tubes bundle. Most commonly used baffles in STHXs are segmental ones which force the shell-side flow to move along a zigzag pattern to enhance heat transfer. Using segmental baffles has major problems such as causing 
dead zones in each compartment between two adjacent segmental baffles and consequently, increase in fouling resistance, and also high risk of vibration failure on tube bundle due to drastic zigzag flow pattern. It has been a while since helical baffles have been suggested as a substitute for segmental baffles [32-34], which reduces the mentioned issues to a great extent.

Regarding the fact that traditional thermal management methods cannot meet the incremental advancement in industries, and also the great potential of nanofluids for heat transfer improvement, more research and studies in this field are strongly felt, particularly on their application in different thermal systems which are practically used in various industries. Further investigations in this field can not only give us the comprehensive insight into nanofluids behavior as novel heat transfer fluids, but also prepare the ground for achieving practical models to be used in industries in near future. In addition, previous studies on the application of nanofluids in STHXs have been conducted in those with conventional segmental baffles the drawbacks of which have been mentioned above. Having these in mind as well as high accuracy of two-phase methods, this study aims to apply the two-phase mixture model in order to numerically investigate the application of nanofluids in the STHX equipped with helical baffles. The effect of different parameters such as the nanofluid concentration as well as geometrical features of the heat exchanger on the hydrothermal characteristics is assessed. Eventually, regarding the increased demand for reducing energy consumption, optimization is performed in order to find optimal cases which provide the maximum heat transfer along with the minimum pressure drop. To our knowledge, the present study is the first report in which the optimal conditions for use of nanofluids in STHX with helical baffles are evaluated.

\section{Methodology}




\subsection{Definition of geometry}

The solution was done for the shell-side of the heat exchanger that has been equipped with helical baffles. The main reason for using such baffles is to overcome the major drawbacks of conventional segmental baffles as discussed above, and at the same time, providing effective mixing in the fluid flowing through the shell-side. To imagine the domain under study, one can consider four quarters of an ellipse with inclined arrangement such that: (1) they could be embedded inside a circle; and (2) flow could be directed towards the next baffle after striking them. It means that the quadrant located at the first quarter of coordinates, guides the flow through the second quarter; the one at the second quarter guides the flow towards the third quarter; and so on. Having passed all four quarters of the coordinate, the flow will traverse a period and return back to its first place. This is the basic principle of helical baffles which forms a rotational pattern for the flow (Fig. 1).

The effect of helix angle, overlapping of two consecutive baffles, and nanoparticle concentration is considered in this contribution. Helix angle is the angle between the normal line of the circular sector-shaped plates and the axis of the heat exchanger. Baffle pitch (i.e., length of a period) is the distance between two similar points from two similar baffles. It should be noted that overlapping (s) is related to baffle pitch $(p)$ by the following equation:

$$
s=1-\frac{p}{2 \sqrt{2} D \tan \beta}
$$

where $D$ represents internal diameter of the shell and $\beta$ is helix angle.

Helix angle and overlapping have been depicted in Fig. 1.

Since the aim is to examine the effect of geometrical parameters and nanoparticle concentration on heat transfer and pressure drop, solutions were carried out at a constant mass flow rate (3.54 
$\mathrm{kg} / \mathrm{s})$. Specifications of the heat exchanger under study are presented in Table 1 . The water$\mathrm{Al}_{2} \mathrm{O}_{3}$ nanofluid was used as the working fluid, and the properties of the base fluid and the nanoparticles have been presented in Table 2. The inlet temperature was considered $340 \mathrm{~K}$ in this study with the tubes surface temperature being $295 \mathrm{~K}$. Moreover, the selected material for baffles and shell of the heat exchanger was stainless steel with thermal conductivity of $15.2 \mathrm{~W} / \mathrm{m} . \mathrm{K}$.

\subsection{Two-phase mixture model}

The two-phase mixture model is used to simulate forced convection of the water- $\mathrm{Al}_{2} \mathrm{O}_{3}$ nanofluid in the STHX with helical baffles. In this approach, which has been shown to be more accurate in prediction of nanofluids behavior than the homogenous single-phase method [35, 36], it is assumed that the coupling between the phases is strong. Also, each phase has its own velocity field and the relative velocity between the phases is taken into account in this method. Considering these assumptions, the conservation equations are as below:

Continuity equation:

$\nabla \cdot\left(\rho_{m} \mathbf{v}_{m}\right)=0$

Momentum equation:

$\nabla \cdot\left(\rho_{m} \mathbf{v}_{m} \mathbf{v}_{m}\right)=-\nabla P+\nabla \cdot\left(\mu_{m} \nabla \mathbf{v}_{m}\right)+\nabla \cdot\left(\varphi_{p} \rho_{p} \mathbf{v}_{d r, p} \mathbf{v}_{d r, p}\right)$

Energy equation:

$\nabla \cdot\left(\left(\varphi_{p} \rho_{p} c_{p, p} \mathbf{v}_{p}+\left(1-\varphi_{p}\right) \rho_{f} c_{p, f} \mathbf{v}_{f}\right) T\right)=\nabla .\left(k_{m} \nabla T\right)$

Volume fraction:

$\nabla .\left(\varphi_{p} \rho_{p} \mathbf{v}_{m}\right)=-\nabla \cdot\left(\varphi_{p} \rho_{p} \mathbf{v}_{d r, p}\right)$

where 
$\mathbf{v}_{m}=\frac{\varphi_{p} \rho_{p} \mathbf{v}_{p}+\left(1-\varphi_{p}\right) \rho_{f} \mathbf{v}_{f}}{\rho_{m}}$

In Eqs. (2)-(6) subscripts $m, p$ and $f$ refer to mixture, particle and base fluid, respectively. In addition, $\rho, \mathbf{v}, \mu, \varphi, c_{p}, k, P$ and $T$ denote density, velocity, dynamic viscosity, concentration, specific heat, thermal conductivity, pressure and temperature, respectively.

In Eq. (3), $\mathbf{v}_{d r, p}$ is the drift velocity for the secondary phase (i.e., nanoparticles) and is defined as below:

$\mathbf{v}_{d r, p}=\mathbf{v}_{p}-\mathbf{v}_{m}$

The slip velocity (relative velocity) is the velocity of the secondary phase $(p)$ relative to the velocity of the primary phase $(f)$ :

$\mathbf{v}_{p f}=\mathbf{v}_{p}-\mathbf{v}_{f}$

and the relation between the drift velocity and the relative velocity is as below:

$\mathbf{v}_{d r, p}=\mathbf{v}_{p f}-\frac{\varphi_{p} \rho_{p}}{\rho_{m}}\left(\mathbf{v}_{f}-\mathbf{v}_{p}\right)$

Considering buoyancy force and Stokes drag for the sub-micron particles, the relative velocity is determined from the equation below:

$\mathbf{v}_{p f}=C_{c} \frac{\rho_{p} d_{p}^{2}}{18 \mu_{f}} \frac{\rho_{p}-\rho_{m}}{\rho_{p}} \mathbf{a}$

The acceleration in Eq. (10) is evaluated by:

$\mathbf{a}=\mathbf{g}-\left(\mathbf{v}_{m} \cdot \nabla\right) \mathbf{v}_{m}$

Moreover, $d_{p}$ is the particle diameter and $C_{c}$ is Cunningham correction factor to Stokes drag law which can be extracted from: 
$C_{c}=1+\frac{2 \lambda}{d_{p}}\left(1.257+0.4 e^{-\left(1.1 d_{p} / 2 \lambda\right)}\right)$

where $\lambda$ represents molecular mean free path for the base fluid, and in this problem, it is considered $0.17 \mathrm{~nm}$ for water.

Eq. (13) is utilized for density of the nanofluid.

$\rho_{m}=\varphi_{p} \rho_{p}+\left(1-\varphi_{p}\right) \rho_{f}$

A temperature-dependent model is used for thermal conductivity, which is taken into account the effect of Brownian motion [37]:

$\frac{k_{m}}{k_{f}}=1+64.7 \varphi^{0.7466}\left(\frac{d_{f}}{d_{p}}\right)^{0.3690}\left(\frac{k_{p}}{k_{f}}\right)^{0.7476}\left(\frac{2.4 \times 10^{-5} \times 10^{\frac{247}{T-140}}}{\rho_{f} \alpha_{f}}\right)^{0.9955}\left(\frac{\rho_{f} k_{B} T}{3 \pi\left(2.4 \times 10^{-5} \times 10^{\frac{247}{T-140}}\right)^{2} \lambda}\right)^{1.232:}$

where $k_{B}$ and $\alpha_{f}$ are Boltzmann constant and thermal diffusivity of the base fluid, respectively, while $d_{f}$ represents molecule size of the base fluid.

Meanwhile, the temperature-dependent model proposed by Masoumi et al. [38] is used to calculate viscosity of the nanofluid as follows:

$\mu_{m}=\mu_{f}+\frac{\rho_{p} V_{B} d_{p}^{2}}{72 C \delta}$

where $\delta$ and $V_{B}$ denote distance between the particles and the Brownian velocity of the nanoparticles, respectively. They can be obtained from equations below:

$$
\begin{aligned}
& V_{B}=\frac{1}{d_{p}} \sqrt{\frac{18 k_{B} T}{\pi \rho_{p} d_{p}}} \\
& \delta=\sqrt[3]{\frac{\pi}{6 \varphi}} d_{p}
\end{aligned}
$$


$C$ is defined as:

$C=\frac{1}{\mu_{f}}\left[\left(c_{1} d_{p}+c_{2}\right) \varphi+\left(c_{3} d_{p}+c_{4}\right)\right]$

where

$c_{1}=-0.000001133, c_{2}=-0.000002771, c_{3}=0.00000009, c_{4}=-0.000000393$

\subsection{Boundary conditions}

The flow regime is turbulent with a mass flow rate of $3.54 \mathrm{~kg} / \mathrm{s}$. The flow pattern repeats at each period due to the existence of an iterative geometry. Therefore, periodic boundary condition is considered for input and output domains of the calculations. This is significantly important in reducing time and cost of calculations. The equations to satisfy this boundary condition are given as below:

$u_{(r, \theta, z)}=u_{(r, \theta, z+p)}$

$v_{(r, \theta, z)}=v_{(r, \theta, z+p)}$

$w_{(r, \theta, z)}=w_{(r, \theta, z+p)}$

$P_{(r, \theta, z)}-P_{(r, \theta, z+p)}=P_{(r, \theta, z+p)}-P_{(r, \theta, z+2 p)}$

where $u, v$ and $w$ are velocity components in the three coordinates.

By a suitable scaling of the fluid temperature for periodically fully developed heat transfer with boundary condition of constant wall temperature:

$\Theta_{(r, \theta, z)}=\frac{T_{(r, \theta, z)}-T_{\text {wall }}}{T_{\text {bulk,inlet }}-T_{\text {wall }}}$

where 
$T_{\text {bulk,inlet }}=\left(\frac{\int T|\rho \mathbf{v . d A}|}{\int|\rho \mathbf{v . d A}|}\right)_{\text {inlet }}$

Considering the periodic condition:

$\Theta_{(r, \theta, z)}=\Theta_{(r, \theta, z+p)}$

Furthermore, shell wall is considered to be adiabatic while boundary condition of constant temperature is implemented on the walls of the tubes.

\subsection{Definition of parameters}

Two parameters namely pressure drop and convective heat transfer coefficient were used to analyze the performance of the STHX.

Convective heat transfer coefficient is defined as below:

$$
h=\frac{Q}{A_{s} \Delta T_{a v e}}
$$

where $Q$ is the rate of heat transfer and is evaluated from the equation below:

$$
Q=\dot{m} c_{p}\left(T_{\text {in }}-T_{\text {out }}\right)
$$

where $\dot{m}$ is the mass flow rate.

Since the heat transfer takes place from surface of the tubes, area of the tubes or heat exchange area $\left(A_{s}\right.$ in Eq. (23)) is calculated as below:

$$
A_{s}=n \pi d p
$$

where $n$ and $d$ denote the number and diameter of tubes, respectively.

$\Delta T_{\text {ave }}$ is the log mean temperature difference which is given by the following equation [39]:

$$
\Delta T_{\text {ave }}=\frac{T_{\text {in }}-T_{\text {out }}}{\ln \left(\left(T_{\text {in }}-T_{\text {wall }}\right) /\left(T_{\text {out }}-T_{\text {wall }}\right)\right)}
$$




\subsection{Numerical method and validation}

A set of 3D coupled non-linear differential equations was discretized using the control volume technique. Grids with different meshes were examined to ensure the grid independency and finer meshing was used around the tubes due to existence of strong temperature and velocity gradients in these regions (Fig. 2). QUICK method was used to solve the convection term, while SIMPLE method was adopted for velocity-pressure coupling. RNG $k-\varepsilon$ model has been utilized for modeling since it is able to model near-wall flows as well as flows with high streamline curvature.

Fig. 3 illustrates the results of investigating mesh independency for $\beta=42^{\circ}$, overlapping of $50 \%$, and $\varphi=1$ vol.\%. For this geometry, as can be observed, for cell numbers more than 1805133 (i.e., $2 \mathrm{~mm}$ distance between nodes of tubes outer surface and $8 \mathrm{~mm}$ distance between nodes of shell inner surface), a significant change does not occur in the results (neither for the convective heat transfer coefficient nor the pressure drop). Hence, this grid is utilized in the simulation.

To validate the numerical approach, the convective heat transfer coefficient obtained from current simulation method was compared with the one obtained from the experimental work of Esmaeilzadeh et al. [40] for the water $-\mathrm{Al}_{2} \mathrm{O}_{3}$ nanofluid flow inside a horizontal tube at $\varphi=1$ vol.\%, $\mathrm{Re}=1300$ and $q^{\prime \prime}=9000 \mathrm{~W} / \mathrm{m}^{2}$. The results are presented in Fig. 4 and as can be seen, there is a good consistency between the results which indicates that the numerical method is valid. In addition, to ensure that the applied meshing for the STHX with helical baffles is appropriate, the results obtained from the current simulation were compared with those reported by Zhang et al. [39] for middle-overlapped helical baffles (i.e., overlapping value of 0.5) at two helix angles of 30 and $50^{\circ}$, the results of which have been listed in Table 3, and as can be seen, there is a good agreement between the results. It should be noted that to make this comparison, the conditions 
have been considered similar to those presented in the study performed by Zhang et al. [39] (i.e., the conductive-320 oil flowing through the shell-side of the heat exchanger with the mass flow rate of $3.5 \mathrm{~kg} / \mathrm{s})$.

\section{Modeling and optimization}

\subsection{Neural network}

Multilayer perceptron neural network was used to model the convective heat transfer coefficient and pressure drop per unit length in terms of helix angle, overlapping and nanoparticle concentration (Fig. 5). This kind of neural network has several layers, with some neurons in each. The neurons in a layer are connected to those of the next layer via coefficients called weight coefficients. The neural network determines the correlation between input and output variables by updating weights and biases. Values of weight coefficients change during training the network. Moreover, an activation function is defined on the neurons of each layer which are applied on the sum of the weighted inputs and the bias of each neuron to generate the neuron output. Making an artificial neural network for modeling includes three following steps: generating required data for training the network, evaluating different structures of the neural network to choose the optimal one, and eventually, testing the neural network using the data not being used previously for training the network.

Backpropagation algorithm, quasi-Newtonian training method and regularization technique were adopted in this modeling. This study benefits from Mean Relative Error (MRE), maximum absolute error and coefficient of determination $\left(R^{2}\right)$ to study performance of the neural network. Moreover, tan-sigmoid activation function was used in the hidden layers while linear activation function was employed in the output layer. Quasi-Newtonian method is based on Newtonian 
method but there is no need to calculate second derivatives. An approximate Hessian matrix is updated in each iteration of the algorithm.

Although the neural network may fit the training data properly, it might be exposed to great error when network validity is evaluated by new data. This problem is called overfitting. It is possible to prevent this problem and improve network generalization by modifying the performance function and the performance function is modified in regularization technique. Performance function is used to calculate the error during the training of the network. The most often used performance function which is applied for feedforward neural networks is mean sum of squares of the network errors which is defined as below:

$m s e=\frac{1}{n} \sum_{i=1}^{n}\left(e_{i}\right)^{2}$

where $e_{i}$ is the difference between desired value and value predicted by the model for each pattern.

In order to modify the performance function, a term including mean of the sum of squares of the network weights was added to the performance function to make the new function as follows:

msenew $=\gamma m s e+(1-\gamma) m s w$

where $m s w$ is the mean of the sum of squares of the weights and $\gamma$ is the performance ratio. Using this performance function causes the neural network to have smaller weights and biases, such that the network will generate smoother answers and thus, network generalization will be improved.

\subsection{Optimization method}


Genetic algorithm was employed to find the optimum parameters, while optimization was conducted on the neural network model. The purpose of optimization in this study is to achieve maximum heat transfer along with minimum pressure drop.

In multi-objective optimizations, a set of cases are obtained as the optimal points, while they have no preference over each other. Therefore, in this research, in addition to performing twoobjective optimization, decision making method of compromise programming was coupled with genetic algorithm in order to facilitate the choosing process among various cases. In this approach, the objective functions are combined together and the problem transforms into a single-objective optimization.

The following equation must be minimized in this technique [41]. Functions $Z$ are objective functions which must be maximized, whereas functions $W$ are those which must be minimized.

$$
D_{b}=\sum_{k=1}^{l} \alpha_{k}^{b}\left[\frac{Z_{k}^{*}-Z_{k}(x)}{Z_{k}^{*}-Z_{k}^{-}}\right]^{b}+\sum_{s=1}^{r} \alpha_{s}^{b}\left[\frac{W_{s}(x)-W_{s}^{*}}{W_{s}^{-}-W_{s}^{*}}\right]^{b}
$$

Superscript “*” denotes the best value for that objective function, while superscript “"” represents the worst value for that objective function. Coefficient $b$ is the distance parameter which is in the range of $1 \leq b \leq \infty$ and in this study, it is taken equal to 2. Coefficients $\alpha$ denote relative importance of the objective functions in comparison with each other. It means that the decision about which objective function of the problem is more important is made before performing the optimization. In fact, the compromised function introduced in Eq. (29) is used in genetic algorithm and importance of each of the objective functions can be modified by changing the $\alpha$ coefficients.

\section{Results and discussion}




\subsection{Physical discussions on results}

In this research, the two-phase mixture model is utilized to simulate the flow and heat transfer of the water- $\mathrm{Al}_{2} \mathrm{O}_{3}$ nanofluid numerically in STHX with helical baffles. The effect of parameters such as nanofluid concentration, helix angle and overlapping between baffles on the convective heat transfer and pressure drop is investigated. Eventually, in order to achieve optimal cases with maximum heat transfer and minimum pressure drop, the optimization is performed by means of genetic algorithm coupled with compromise programming technique on the model developed from neural network.

Figure 6 illustrates velocity vectors of the flow in front view of STHX for $\beta=30^{\circ}$ and $s=0.6$. As can be seen, using of the helical baffles leads to induction of a secondary flow in STHX. It means that the fluid flows not only along the axial direction, but also perpendicular to STHX axis. Therefore, the mixing is intensified in the shell side, which can lead to improvement of the heat transfer from the tubes to the fluid flowing inside the shell. Furthermore, the mixing developed in the flow, particularly in case of using the nanofluid, can efficiently avoid sedimentation and agglomeration of the nanoparticles in STHX.

This mixing can be clearly seen in Figure 7a in which velocity vectors of the flow have been shown in a zoomed part of the transverse cross section of STHX for $\beta=30^{\circ}$ and $s=0.6$. It is observed that due to the secondary flow induced in the shell side, the fluid flows perpendicular to the tubes in STHX, and as mentioned before, this can enhance the rate of heat transfer from the tubes to the fluid inside the shell and consequently, improve the efficiency. Figure 7b illustrates temperature contour in the same part of the transverse cross section for similar conditions. It can be simply understood that the cross flow occurred in the shell side causes disturbances in the developing thermal boundary layer on the tubes, which can improve the rate of heat transfer. 
Moreover, besides providing a more efficient heat transfer, the nanofluid which is flowing between the tubes incorporates a relatively uniform distribution of temperature which can prevent thermal stresses due to very large temperature difference in STHX.

In Figure 8a, the effect of nanofluid concentration and baffles overlapping is demonstrated on the convective heat transfer coefficient at $\beta=30^{\circ}$. It is noticed that increasing the nanofluid concentration leads to a greater convective heat transfer coefficient, such that increasing the concentration from 1 to $5 \%$ in almost every values of the baffles overlapping under study enhances the convective heat transfer coefficient by about $14 \%$. The reason is that as mentioned in the relevant literature, increase in nanoparticle concentration will improve thermal properties of nanofluids, including their thermal conductivity. Thus, in case of using nanofluids as the heat transfer fluids, it contributes to a greater convective heat transfer. Moreover, it is seen that the rate of enhancement in the convective heat transfer coefficient decreases by increasing of the nanofluid concentration. For instance, at $s=0.3$ increasing of the concentration from 1 to $2 \%$ and from 4 to $5 \%$ will improve the convective heat transfer coefficient by approximately 4.8 and $2 \%$, respectively. This can be due to the nonlinear relation of the thermal conductivity with the nanofluid concentration (see Eq. (14)). Another point which can be inferred from this figure is that the convective heat transfer coefficient increases almost linearly with the overlapping increment. As per Eq. (1), a greater overlapping at a constant helix angle leads to decrease in the baffle pitch and thus, the distance between two consecutive baffles. Hence, a greater flow mixing is developed as a result of flow striking the baffles, which can be regarded as the reason for the increased convective heat transfer coefficient with increasing the overlapping. Figure 8b shows the convective heat transfer coefficient in terms of helix angle for different values of overlapping at $\varphi=3 \mathrm{vol} . \%$. It is seen that using helical baffles with smaller helix angles 
provides higher values of the convective heat transfer coefficient. The reason is that for smaller values of the helix angle, the flow behavior becomes more similar to the cross flow condition and thus, the fluid will experience a more severe mixing. This means that at smaller helix angles, the velocity vectors in the transverse cross section of STHX (i.e., the velocity component perpendicular to pipes axis) will be greater. It is also noticed that the convective heat transfer coefficient increases by increasing the overlapping. However, the important issue here is that the effect of the overlapping change on the convective heat transfer coefficient is rather severe at smaller helix angles, such that by increasing the overlapping from 0 to 0.6 , the amount of enhancement in the convective heat transfer coefficient for the helix angles of 30 and $50^{\circ}$ is 5.5 and $2 \%$, respectively.

In Figure 9a, the pressure drop per unit length of STHX is shown in terms of baffles overlapping for different concentrations of the nanoparticles at $\beta=42^{\circ}$. As can be seen, application of the nanofluids with a higher concentration leads to a greater pressure drop in STHX. The reason for such an observation could be attributed to the fact that the more the concentration of the dispersed nanoparticles, the greater the viscosity of the nanofluid. Meanwhile, in Figure 9a, it is seen that despite Figure 8a in which the rate of the enhancement in the convective heat transfer coefficient was decreasing by raising the nanofluid concentration, the rate of the enhancement in pressure drop is ascending by increasing the nanofluid concentration. For example at $s=0.6$, by increasing the concentration from 1 to $2 \%$ and from 4 to $5 \%$, the pressure drop per unit length increases by about 1 and 3.2\%, respectively. Moreover, it is observed in this figure that application of the baffles with larger overlapping generally leads to a greater pressure drop in STHX. As mentioned above, at greater values of overlapping, the flow strikes the baffles more severely and hence, a higher pumping power will be required due to the more intense mixing. 
Figure 9b depicts the effect of helix angle and baffles overlapping on the pressure drop per unit length of STHX for $\varphi=5$ vol.\%. It is observed that at a constant overlapping, the greater the helix angle, the lower the pressure drop. The reason is related to the fact that as the helix angle increases, the flow behavior recedes from the cross flow state, which will in turn lead to less intense mixing in the flow. The more significant effect of variation in the overlapping on the pressure drop at smaller helix angles can be clearly seen in this figure, such that at the helix angles of 30 and $50^{\circ}$, by increasing the overlapping from 0 to 0.6 , the amount of enhancement in the pressure drop is reported to be 105 and $38.6 \%$, respectively.

\subsection{Results related to modeling and optimization}

As was seen, each of the parameters related to geometry and nanofluid (i.e., concentration of nanoparticles, baffles overlapping and helix angles), has different effects on the convective heat transfer coefficient and pressure drop in STHX. For instance, reduction of the helix angle will increase the pressure drop in addition to the heat transfer increment. Therefore, finding optimal conditions which could simultaneously lead to the maximum convective heat transfer and the minimum pressure drop seems to be rather essential. The first step in optimization of the problem under study is to find the models for the objective functions (i.e., convective heat transfer coefficient $(h)$ and pressure drop $(\Delta P))$ in terms of input effective parameters. For this purpose, the neural network was used, in which concentration of the nanofluid, baffles overlapping and helix angle were the inputs, while $h$ and $\Delta P$ were the network outputs (Figure 5).

The most significant part of modeling via neural network is to generate the data required for training the network, such that the developed model can properly predict the problem under study. The data obtained from numerical solutions were used for training the neural network. The 
numerical simulations were carried out at five different concentrations ( $\varphi=1,2,3,4$ and 5 vol.\%), six different helix angles $\left(\beta=30,34,38,42,46\right.$ and $\left.50^{\circ}\right)$ and seven different baffles overlapping $(s=0,0.1,0.2,0.3,0.4,0.5$ and 0.6$)$, providing 210 data points, 190 of which were used for training the neural network, while the remaining were allocated to validation of the model. In order to improve accuracy of the network, all the data were scaled in the range of [-1 1 $]$. Numerous structures were examined to reach a network which is well capable of predicting the results and finally, a network with a hidden layer having 12 neurons was chosen as the best network. For the test data, the obtained model predicts the amount of convective heat transfer coefficient with $R^{2}$ and MRE values of about 0.9991 and $0.089 \%$, respectively, and predicts the pressure drop with $R^{2}$ and MRE values of about 0.9998 and $0.65 \%$, respectively. Maximum absolute errors for the test data set in estimation of $h$ and $\Delta P$ were approximately 2.19 and 1.57 , respectively. This indicates that the developed model can predict the problem outputs with a great accuracy throughout the domain under study. The comparison between the results obtained from this model and those derived from the numerical solution is illustrated in Figure 10 for the test data. The results are found to be very consistent, which implies that the neural network model is valid.

In order to obtain the optimal conditions with the maximum heat transfer and the minimum pressure drop, the optimization has been performed using the genetic algorithm on the model developed from the neural network. The problem under study is a two-objective optimization in which $h$ and $\Delta P$ should be maximized and minimized, respectively. Pareto diagram and 15 optimal states obtained from optimization have been presented in Figure 11 and Table 4, respectively. In addition to the optimal values of the objective functions, the values related to the input variables which lead to these optimal states have also been reported in Table 4 . 
The optimal cases obtained from the two-objective optimization using the above mentioned method have no advantage over each other and there is no specific criterion for decision making among them. Therefore, genetic algorithm coupled with compromise programming technique was utilized to facilitate the process of selecting among the optimal states for the decision maker, in which the objective functions are combined with each other and the problem is converted to a single-objective optimization. Since there are two objective functions in this research (one for the convective heat transfer coefficient which must be maximized and the other for the pressure drop which must be minimized), Eq. (29) is converted to the following form:

$$
D_{2}=\alpha_{1}\left[\frac{h^{*}-h}{h^{*}-h^{-}}\right]^{2}+\alpha_{2}\left[\frac{\Delta P-\Delta P^{*}}{\Delta P^{-}-\Delta P^{*}}\right]^{2}
$$

According to the above equation in which coefficients $\alpha$ indicate relative importance of the objective functions, this problem has been solved for different combinations of the coefficients $\alpha$. In fact, $D_{2}$ is the new objective function which must be minimized. Table 5 summarizes the optimal states obtained from this method. It should be noted that $\alpha_{1}$ and $\alpha_{2}$ denote the relative importance of the objective functions related to the convective heat transfer coefficient and pressure drop, respectively, and their sum must be equal to 1 .

It is observed that when all the importance is assigned to the objective function of pressure drop (i.e., first row of the table), concentration and baffles overlapping are obtained in their minimum values, whereas the helix angle shows its maximum value. The reason is that as shown in Figure 9, increasing the concentration and consequently, raising the nanofluid viscosity leads to greater pressure drop in STHX. Meanwhile, reduction of the helix angle and increasing the baffles overlapping will increase mixing in the heat exchanger and thus, the pressure drop. On the other hand, when the objective function of convective heat transfer coefficient is regarded to have the 
most relative importance (i.e., last row of the table), the conditions are completely vice versa as compared to the above case, such that both concentration and baffles overlapping have their maximum values, but the helix angle meets its minimum value.

With increase in the relative importance of the objective function of heat transfer (i.e., with increasing the value of $\alpha_{1}$ ), the concentration increases rapidly and reaches its maximum value (i.e., $\varphi=5$ vol.\%), while the helix angle decreases gradually and reaches its minimum value (i.e., $\beta=30^{\circ}$ ) nearly in the middle rows of the table (where the relative importance for both objective functions are almost the same). However, the amount of overlapping remains approximately constant in its low values. It can be inferred from the trend of the obtained data that the effect of nanoparticle concentration is much more significant on the convective heat transfer in comparison with the pressure drop. Therefore, it is possible to use high concentration nanofluids even if a low pressure drop in the heat exchanger is of great importance for the designer. It can be observed that the helix angle has somewhat more significant effect on the convective heat transfer coefficient as compared to the pressure drop, since it demonstrates its minimum value for cases with the same relative importance for both objective functions. It means that when both high heat transfer and low pressure drop are critical for the decision maker, the helical baffles with small helix angle can be used, which will introduce an effective mixing in the flow. In addition, the trend of changes in overlapping as listed in the table shows that application of the helical baffles with high values of overlapping is only recommended when, from the designer's point of view, improvement of heat transfer is regarded to be much more important than the reduction of the pressure drop.

Although the flow and heat transfer characteristics of the nanofluid were evaluated in STHX with helical baffles in this contribution and the optimal states were proposed to achieve the 
maximum heat transfer and the minimum pressure drop, regarding the very few studies conducted on nanofluids flow in such geometries, further numerical and experimental investigations are needed to be performed to characterize behavior of nanofluids in this type of heat exchangers.

\section{Conclusion}

Hydrothermal characteristics of the water- $\mathrm{Al}_{2} \mathrm{O}_{3}$ nanofluid were assessed in STHX equipped with helical baffles using the two-phase mixture numerical method. Increasing concentration of the nanoparticles, increasing the baffles overlapping and also reducing the helix angle all led to greater values of heat transfer and pressure drop. The effect of changing the overlapping on the convective heat transfer coefficient and the pressure drop is more significant at smaller helix angles. By means of neural network, the models of convective heat transfer coefficient and pressure drop of the nanofluid in STHX were found with a very good accuracy in terms of the effective parameters, namely concentration of the nanoparticles, baffles overlapping and helix angle, and were used as the objective functions in the optimization. The results obtained from optimization revealed that due to the greater effect of overlapping on the pressure drop in comparison with its effect on the heat transfer, using great overlapping values is suggested only when heat transfer improvement is significantly more important than the pressure drop reduction. In addition, high concentrations of the nanofluid can even be employed when a low pressure drop is really important. Moreover, when both high heat transfer and low pressure drop are important, a small helix angle can be used. 


\section{References}

[1] Bahiraei M, Hangi M. Flow and heat transfer characteristics of magnetic nanofluids: A review. Journal of Magnetism and Magnetic Materials. 2015;374:125-38.

[2] Xia HH, Tang GH, Shi Y, Tao WQ. Simulation of heat transfer enhancement by longitudinal vortex generators in dimple heat exchangers. Energy. 2014;74:27-36.

[3] Zhang J-F, Guo S-L, Li Z-Z, Wang J-P, He Y-L, Tao W-Q. Experimental performance comparison of shell-andtube oil coolers with overlapped helical baffles and segmental baffles. Applied Thermal Engineering. 2013;58(12):336-43.

[4] Zheng Z, Fletcher DF, Haynes BS. Chaotic advection in steady laminar heat transfer simulations: Periodic zigzag channels with square cross-sections. International Journal of Heat and Mass Transfer. 2013;57(1):274-84.

[5] SUS Choi. Enhancing thermal conductivity of fluids with nanoparticles in: Developments and Applications of Non-Newtonian Flows, Singer DA and Wang HP editors, Proceeding of the ASME International Mechanical Engineering Congress. New York: ASME; 1995. p. 99-105.

[6] Ilyas SU, Pendyala R, Marneni N. Preparation, sedimentation, and agglomeration of nanofluids. Chemical Engineering \& Technology. 2014;37(12):2011-21.

[7] Haddad Z, Abid C, Oztop HF, Mataoui A. A review on how the researchers prepare their nanofluids. International Journal of Thermal Sciences. 2014;76:168-89.

[8] Celen A, Çebi A, Aktas M, Mahian O, Dalkilic AS, Wongwises S. A review of nanorefrigerants: Flow characteristics and applications. International Journal of Refrigeration. 2014;44:125-40.

[9] Ciloglu D, Bolukbasi A. A comprehensive review on pool boiling of nanofluids. Applied Thermal Engineering. 2015;84:45-63.

[10] Verma SK, Tiwari AK. Progress of nanofluid application in solar collectors: A review. Energy Conversion and Management. 2015;100:324-46.

[11] Bianco V, Chiacchio F, Manca O, Nardini S. Numerical investigation of nanofluids forced convection in circular tubes. Applied Thermal Engineering. 2009;29(17-18):3632-42.

[12] Izadi M, Behzadmehr A, Jalali-Vahida D. Numerical study of developing laminar forced convection of a nanofluid in an annulus. International Journal of Thermal Sciences. 2009;48(11):2119-29. 
[13] Namburu PK, Das DK, Tanguturi KM, Vajjha RS. Numerical study of turbulent flow and heat transfer characteristics of nanofluids considering variable properties. International Journal of Thermal Sciences. 2009;48(2):290-302.

[14] Haghshenas Fard M, Esfahany MN, Talaie MR. Numerical study of convective heat transfer of nanofluids in a circular tube two-phase model versus single-phase model. International Communications in Heat and Mass Transfer. 2010;37(1):91-7.

[15] Bahiraei M, Hosseinalipour SM. Thermal dispersion model compared with Euler-Lagrange approach in simulation of convective heat transfer for nanoparticle suspensions. Journal of Dispersion Science and Technology. 2013;34(12):1778-89.

[16] Naphon P, Nakharintr L. Numerical investigation of laminar heat transfer of nanofluid-fcooled mini-rectangular fin heat sinks. J Eng Phys Thermophy. 2015;88(3):666-75.

[17] Bahremand H, Abbassi A, Saffar-Avval M. Experimental and numerical investigation of turbulent nanofluid flow in helically coiled tubes under constant wall heat flux using Eulerian-Lagrangian approach. Powder Technology. 2015;269:93-100.

[18] Narrein K, Sivasankaran S, Ganesan P. Two-phase analysis of a helical microchannel heat sink using nanofluids. Numerical Heat Transfer, Part A: Applications. 2015;68(11):1266-79.

[19] Khoshvaght-Aliabadi M. Thermal performance of plate-fin heat exchanger using passive techniques: vortexgenerator and nanofluid. Heat Mass Transfer. 2015; in press, doi: 10.1007/s00231-015-1603-6.

[20] Durga Prasad PV, Gupta AVSSKS, Sreeramulu M, Sundar LS, Singh MK, Sousa ACM. Experimental study of heat transfer and friction factor of $\mathrm{Al} 2 \mathrm{O} 3$ nanofluid in U-tube heat exchanger with helical tape inserts. Experimental Thermal and Fluid Science. 2015;62:141-50.

[21] Elias MM, Miqdad M, Mahbubul IM, Saidur R, Kamalisarvestani M, Sohel MR, et al. Effect of nanoparticle shape on the heat transfer and thermodynamic performance of a shell and tube heat exchanger. International Communications in Heat and Mass Transfer. 2013;44:93-9.

[22] Elias MM, Shahrul IM, Mahbubul IM, Saidur R, Rahim NA. Effect of different nanoparticle shapes on shell and tube heat exchanger using different baffle angles and operated with nanofluid. International Journal of Heat and Mass Transfer. 2014;70:289-97. 
[23] Ghozatloo A, Rashidi A, Shariaty-Niassar M. Convective heat transfer enhancement of graphene nanofluids in shell and tube heat exchanger. Experimental Thermal and Fluid Science. 2014;53:136-41.

[24] Shahrul, I. M., Mahbubul, I. M., Saidur, R., Sabri, M. F. M., \& Khaleduzzaman, S. S. (2014). Energy and Environmental Effects of Shell and Tube Heat Exchanger by Using Nanofluid as a Coolant. Journal of Chemical Engineering of Japan, 47(4), 340-344.

[25] Raja, M., Arunachalam, R., \& Suresh, S. (2012). Experimental studies on heat transfer of alumina/water nanofluid in a shell and tube heat exchanger with wire coil insert. International Journal of Mechanical and Materials Engineering, 7(1), 16-23.

[26] R. Lotfi, A.M. Rashidi, A. Amrollahi, Experimental study on the heat transfer enhancement of MWNT-water nanofluid in a shell and tube heat exchanger, International Communications in Heat and Mass Transfer, 39 (2012) $108-111$.

[27] J. Sarkar, Performance of nanofluid-cooled shell and tube gas cooler in transcritical CO2 refrigeration systems, Applied Thermal Engineering, 31 (2011) 2541-2548.

[28] L. Godson, K. Deepak, C. Enoch, B. Jefferson, B. Raja, Heat transfer characteristics of silver/water nanofluids in a shell and tube heat exchanger, Archives of Civil and Mechanical Engineering, 14 (2014) 489-496.

[29] Shahrul IM, Mahbubul IM, Saidur R, Khaleduzzaman SS, Sabri MFM, Rahman MM. Effectiveness Study of a Shell and Tube Heat Exchanger Operated with Nanofluids at Different Mass Flow Rates. Numerical Heat Transfer, Part A: Applications. 2014;65(7):699-713.

[30] Farajollahi B, Etemad SG, Hojjat M. Heat transfer of nanofluids in a shell and tube heat exchanger. International Journal of Heat and Mass Transfer. 2010;53(1-3):12-7.

[31] M. Bahiraei, S.M. Hosseinalipour, M. Saeedan, Prediction of Nusselt number and friction factor of water- $\mathrm{Al}_{2} \mathrm{O}_{3}$ nanofluid flow in shell-and-tube heat exchanger with helical baffles, Chem. Eng. Commun. 202 (2015) 260-268.

[32] Dong C, Chen Y-P, Wu J-F. Flow and heat transfer performances of helical baffle heat exchangers with different baffle configurations. Applied Thermal Engineering. 2015;80:328-38.

[33] Gao B, Bi Q, Nie Z, Wu J. Experimental study of effects of baffle helix angle on shell-side performance of shell-and-tube heat exchangers with discontinuous helical baffles. Experimental Thermal and Fluid Science. 2015;68:48-57. 
[34] Lei Y-G, He Y-L, Chu P, Li R. Design and optimization of heat exchangers with helical baffles. Chemical Engineering Science. 2008;63(17):4386-95.

[35] Khoshvaght-Aliabadi M, Hormozi F, Zamzamian A. Effects of geometrical parameters on performance of plate-fin heat exchanger: Vortex-generator as core surface and nanofluid as working media. Applied Thermal Engineering. 2014;70(1):565-79.

[36] Lotfi R, Saboohi Y, Rashidi AM. Numerical study of forced convective heat transfer of Nanofluids: Comparison of different approaches. International Communications in Heat and Mass Transfer. 2010;37(1):74-8.

[37] Chon CH, Kihm KD, Lee SP, Choi SUS. Empirical correlation finding the role of temperature and particle size for nanofluid (Al2O3) thermal conductivity enhancement. Applied Physics Letters. 2005;87(15):153107.

[38] Masoumi N, Sohrabi N, Behzadmehr A. A new model for calculating the effective viscosity of nanofluids. Journal of Physics D: Applied Physics. 2009;42(5):055501.

[39] Zhang J-F, He Y-L, Tao W-Q. 3D numerical simulation on shell-and-tube heat exchangers with middleoverlapped helical baffles and continuous baffles - Part II: Simulation results of periodic model and comparison between continuous and noncontinuous helical baffles. International Journal of Heat and Mass Transfer. 2009;52(23-24):5381-9.

[40] Esmaeilzadeh E, Almohammadi H, Nasiri Vatan S, Omrani AN. Experimental investigation of hydrodynamics and heat transfer characteristics of $\gamma$-Al2O3/water under laminar flow inside a horizontal tube. International Journal of Thermal Sciences. 2013;63:31-7.

[41] Kumar DN. Multicriterion Analysis in Engineering and Management. New Delhi: PHI Learning, 2010. 


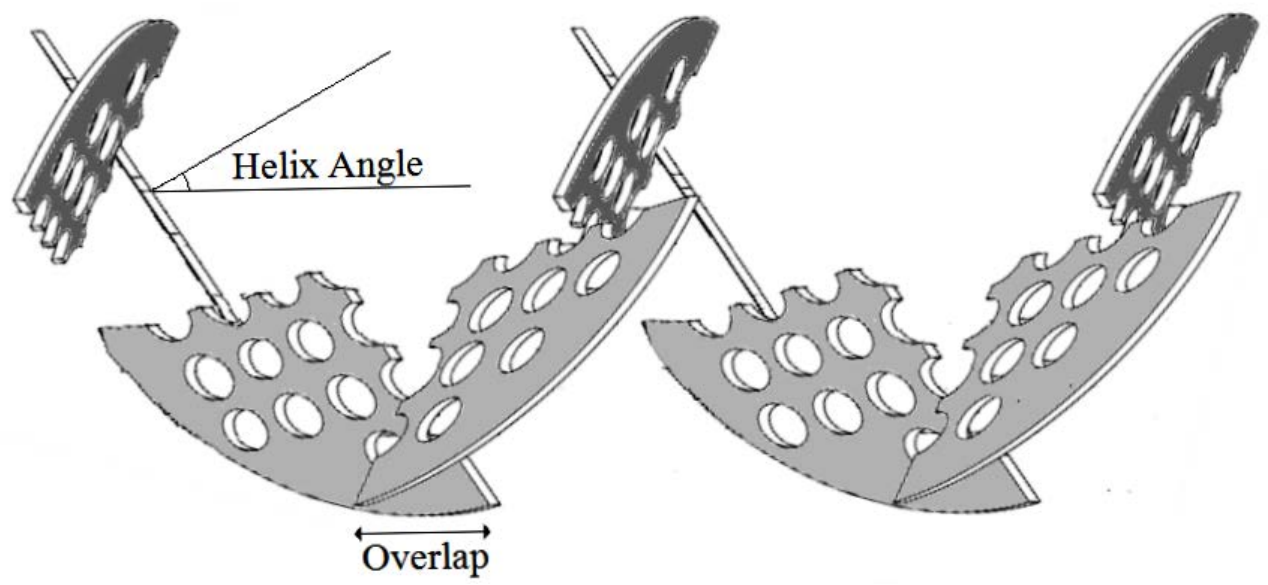

Fig. 1. Schematic view of helical baffles 


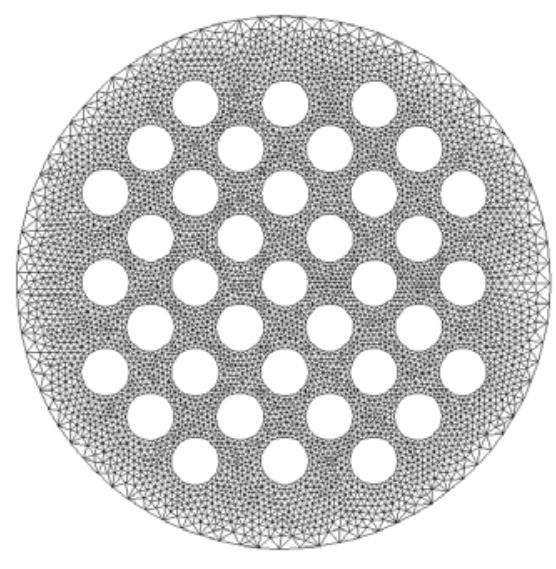

Fig. 2. Transverse cross section of the computational domain 


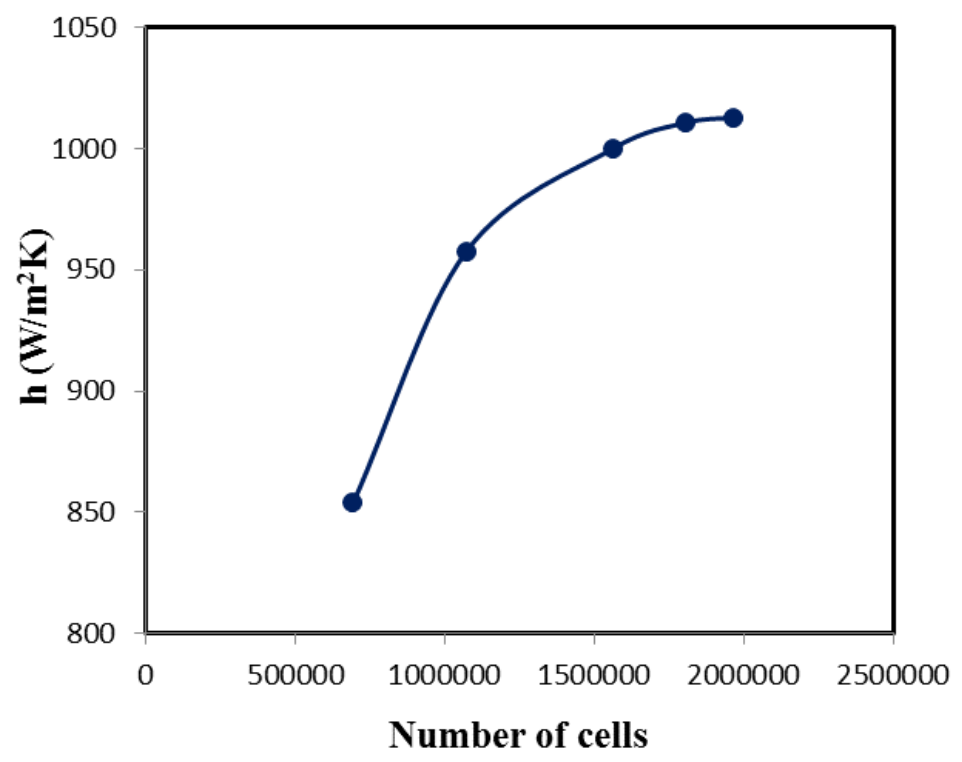

(a)

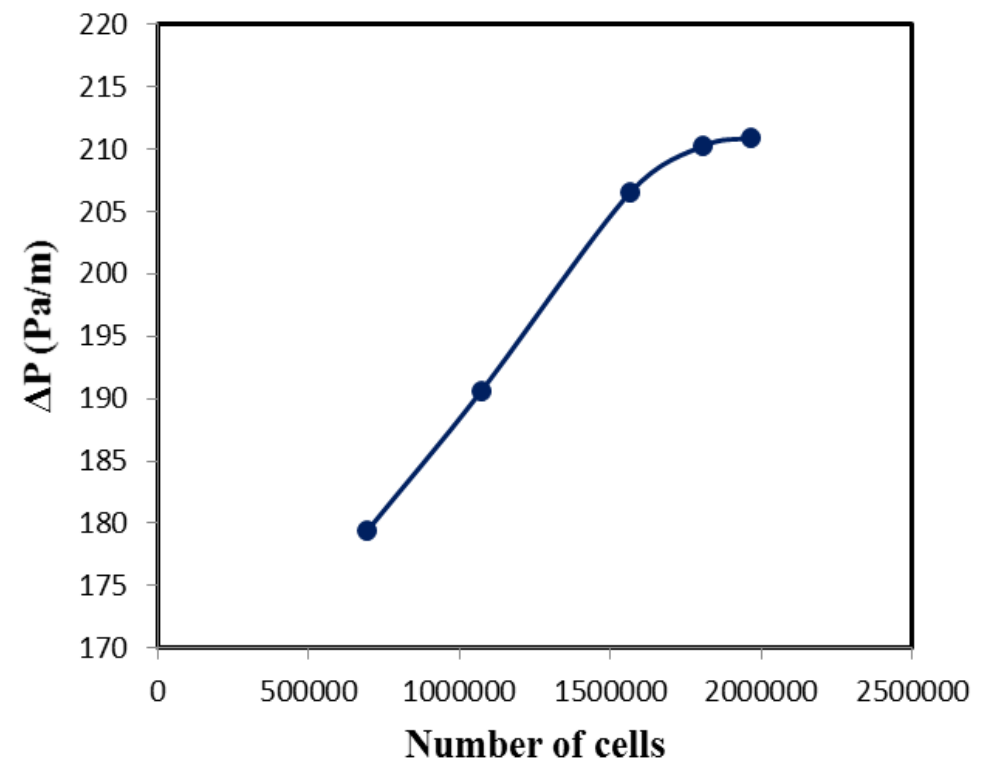

(b)

Fig. 3. Grid independency investigation; a) $h$, b) $\Delta P$ 


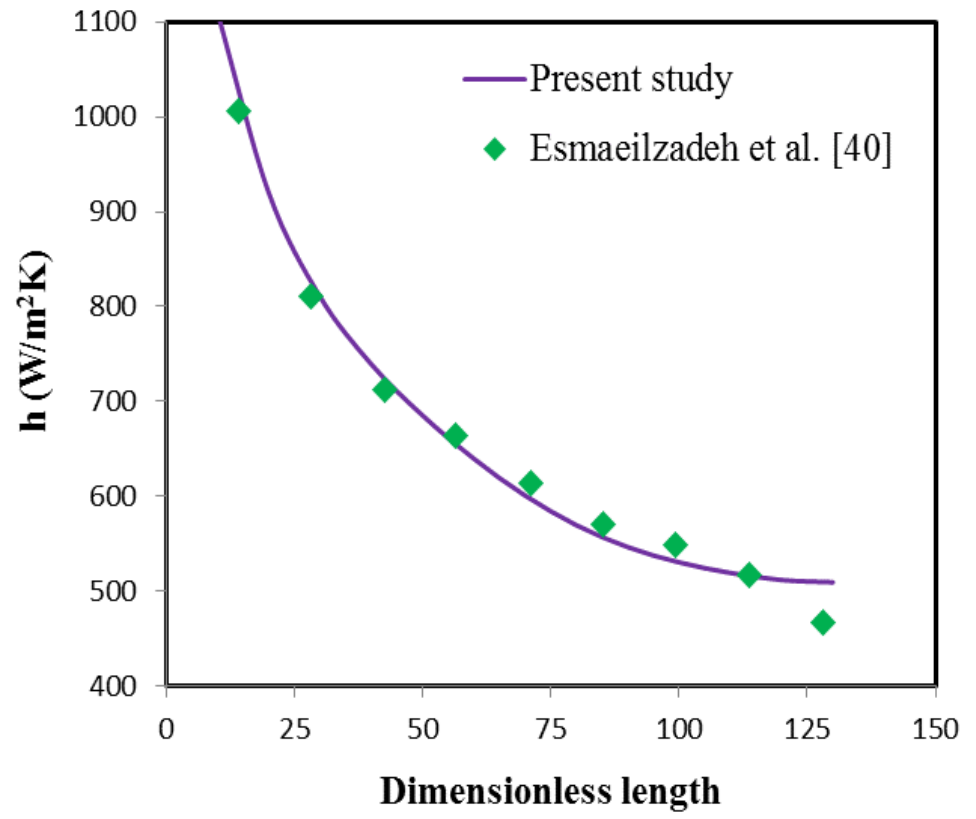

Fig. 4. Convective heat transfer coefficient obtained from current simulation method in comparison with the one obtained from the experimental work of Esmaeilzadeh et al. [40]. 


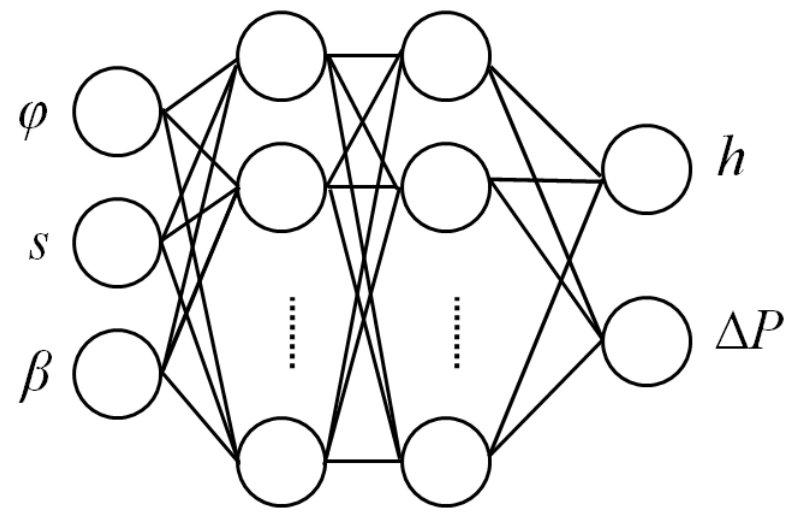

Fig.5. Structure of neural network. 


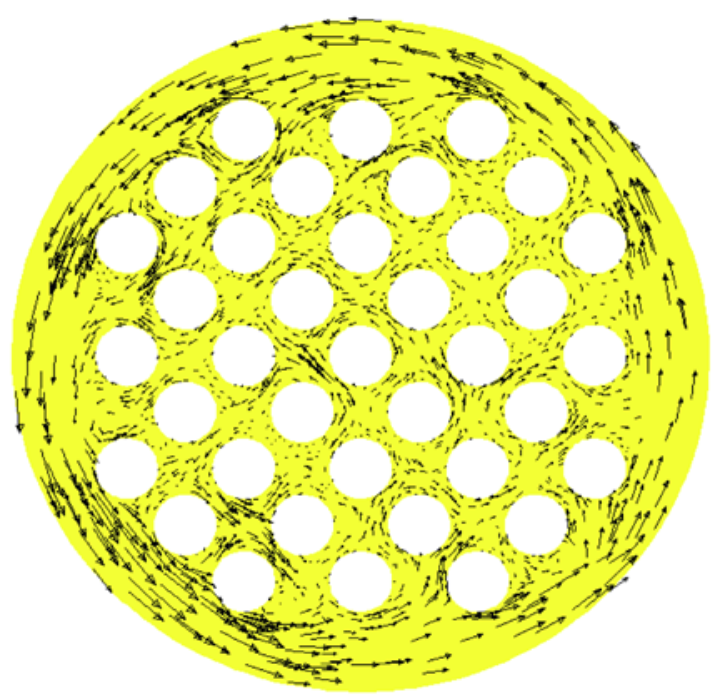

Fig. 6. Velocity vectors in front view of STHX for $\beta=30^{\circ}$ and $s=0.6$. 


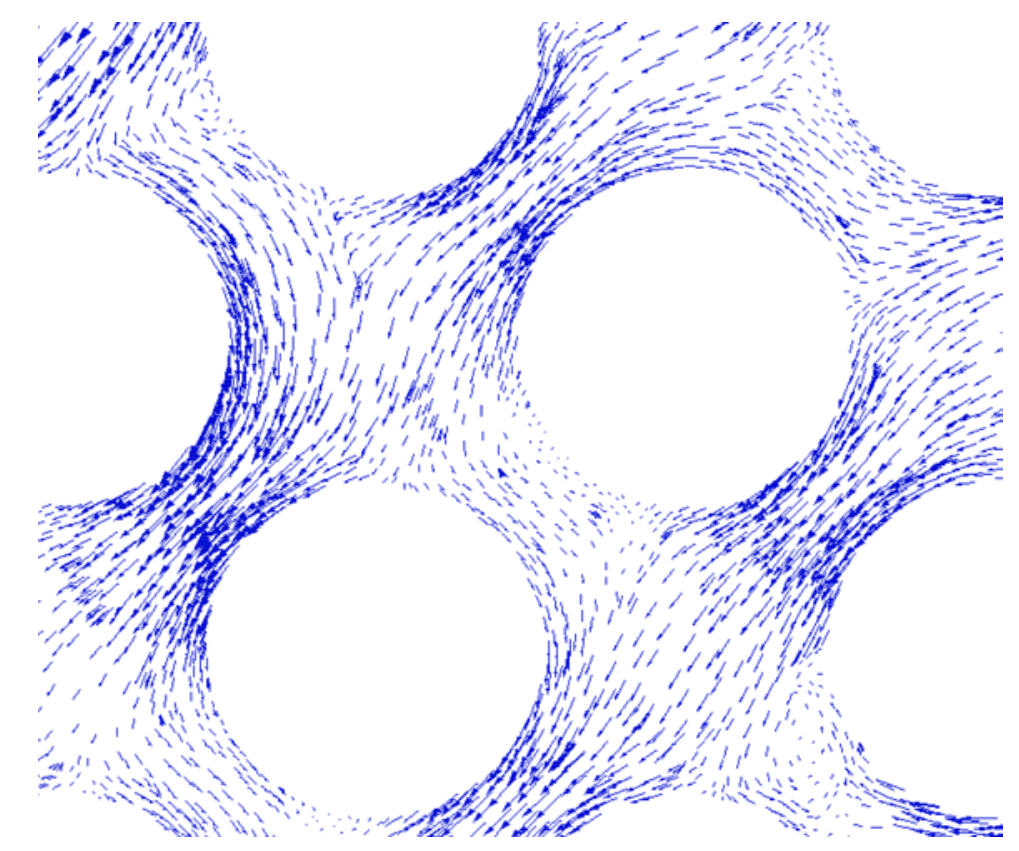

(a)

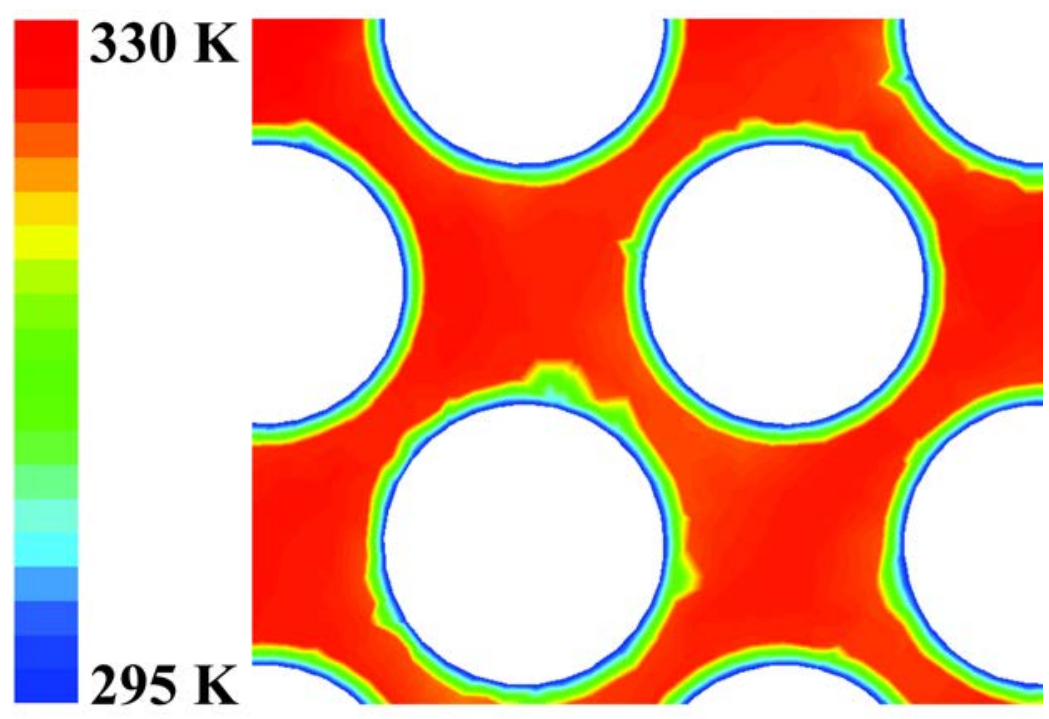

(b)

Fig 7. a) Velocity vectors of the flow, b) Temperature contour; in a part of the transverse cross section of the STHX for $\beta=30^{\circ}$ and $s=0.6$. 


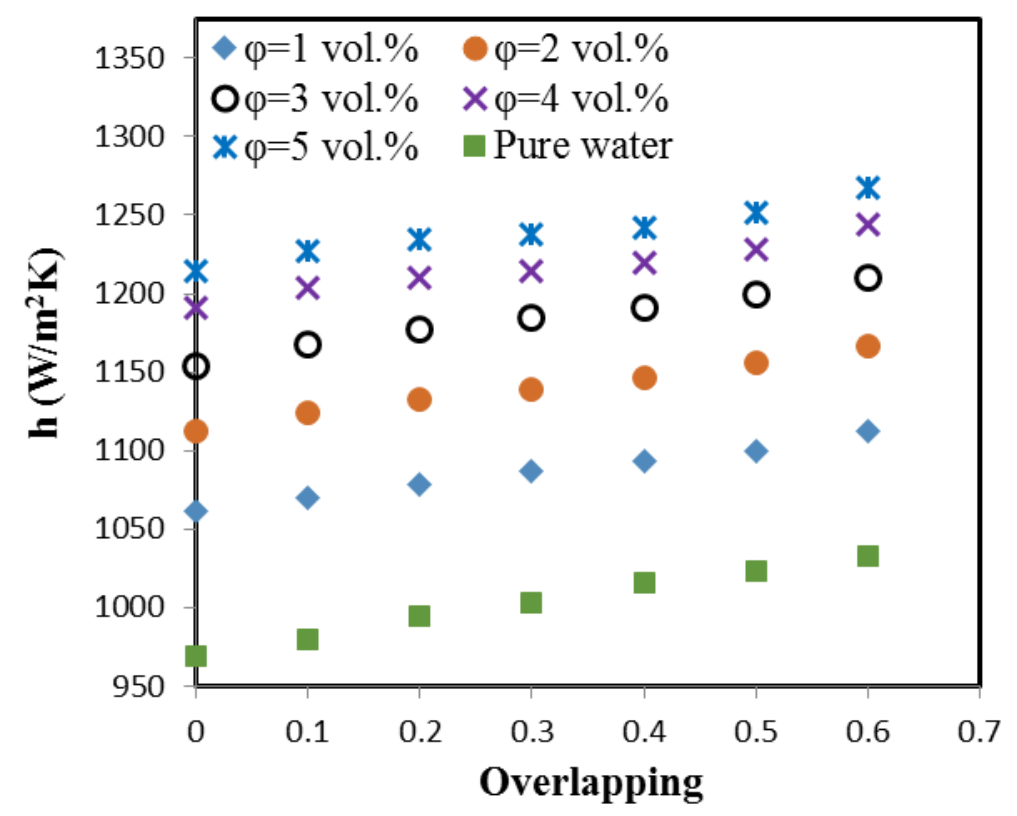

(a)

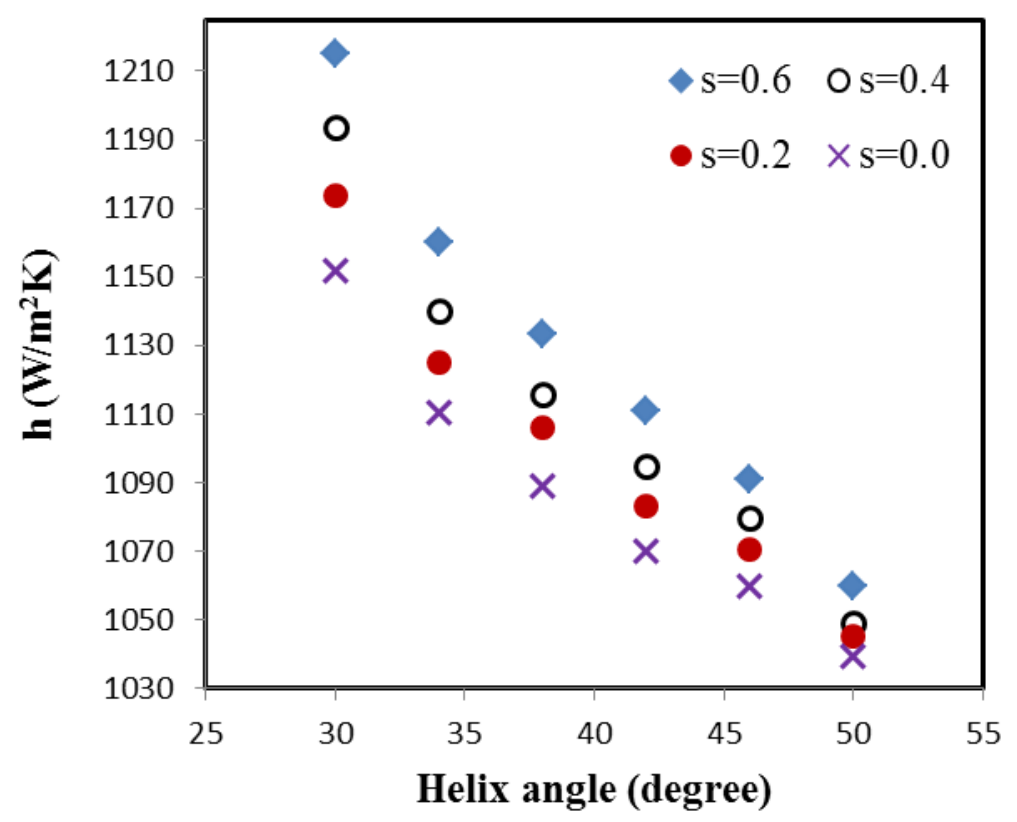

(b)

Fig. 8. Convective heat transfer coefficient; a) in terms of baffles overlapping at different concentrations for $\beta=30^{\circ}$, b) in terms of helix angle at different values of overlapping for $\varphi=3$ vol.\%. 


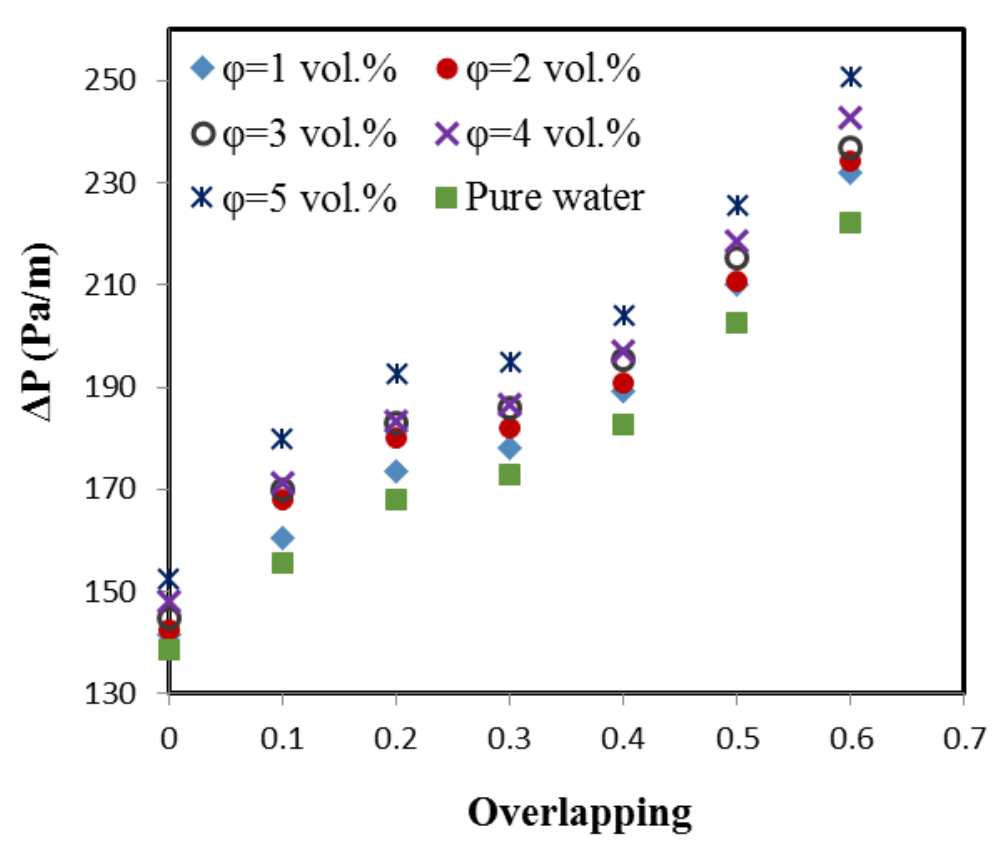

(a)

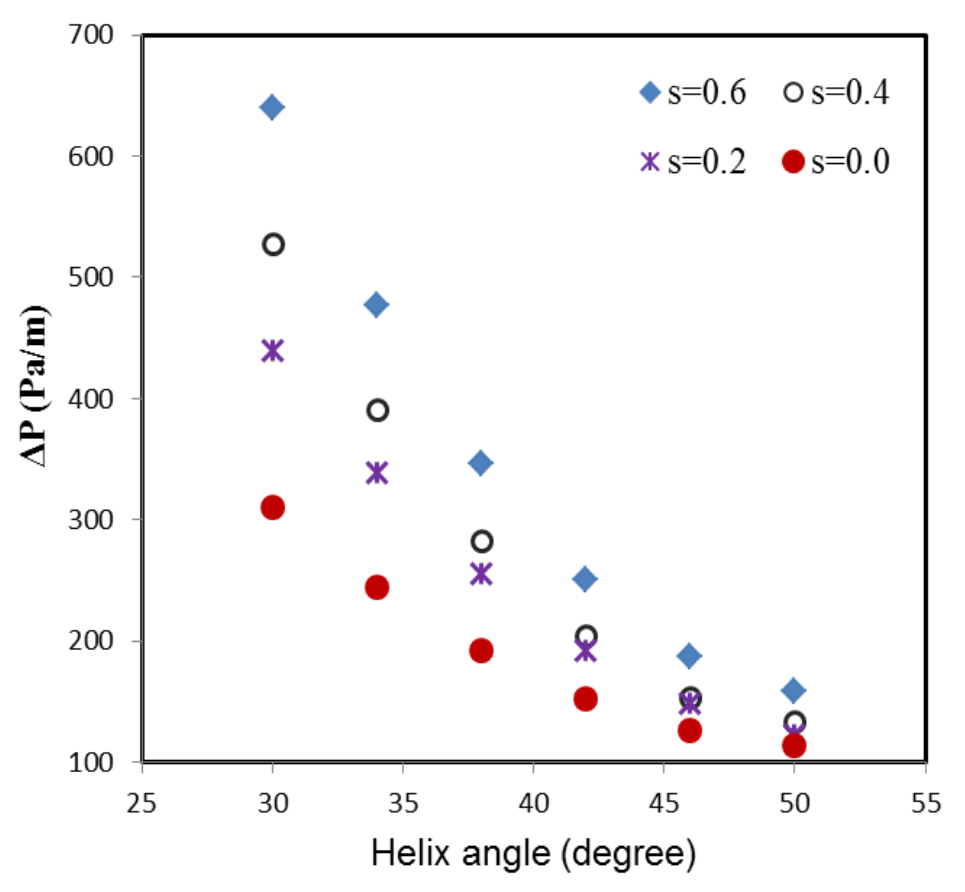

(b)

Fig. 9. Pressure drop per unit length of STHX; a) in terms of baffles overlapping at different concentrations for $\beta=42^{\circ}$, b) in terms of helix angle at different values of baffles overlapping for $\varphi=5$ vol. $\%$. 


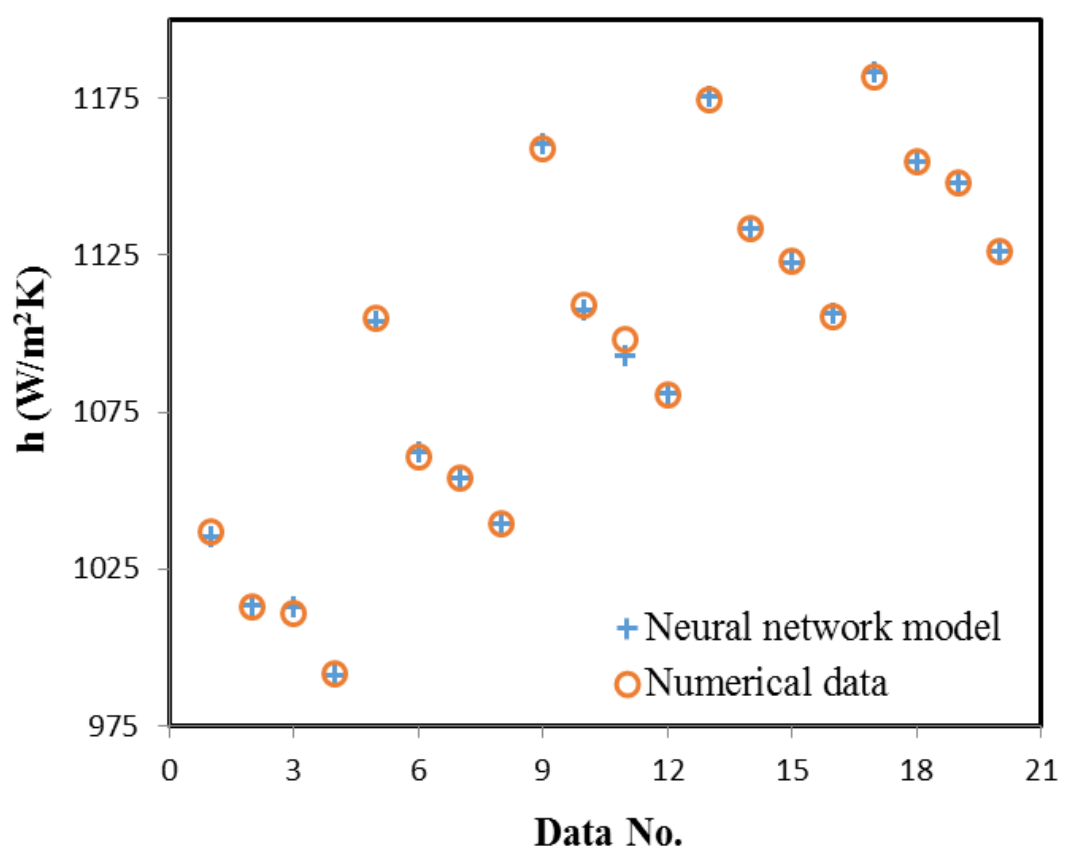

(a)

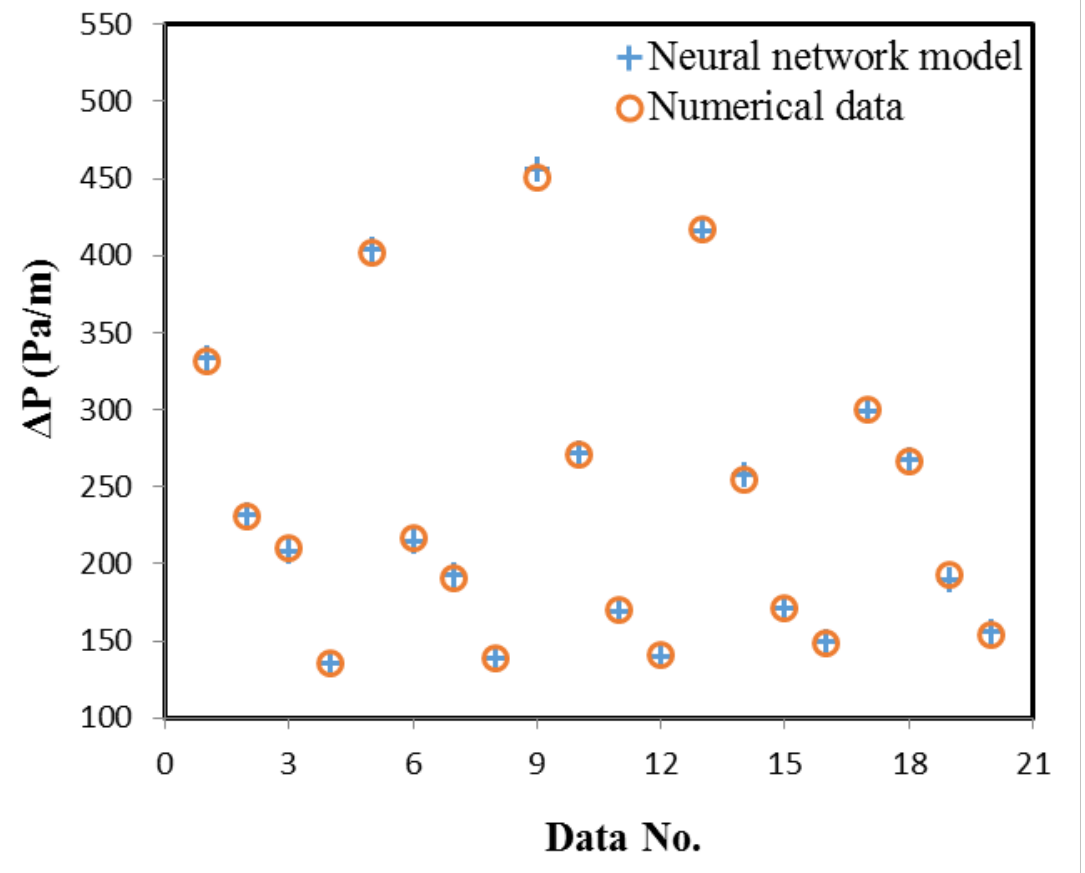

(b)

Fig. 10. Comparison between the results obtained from the neural network model and those derived from the numerical simulation for the test data; a) convective heat transfer coefficient, b) pressure drop per unit length. 


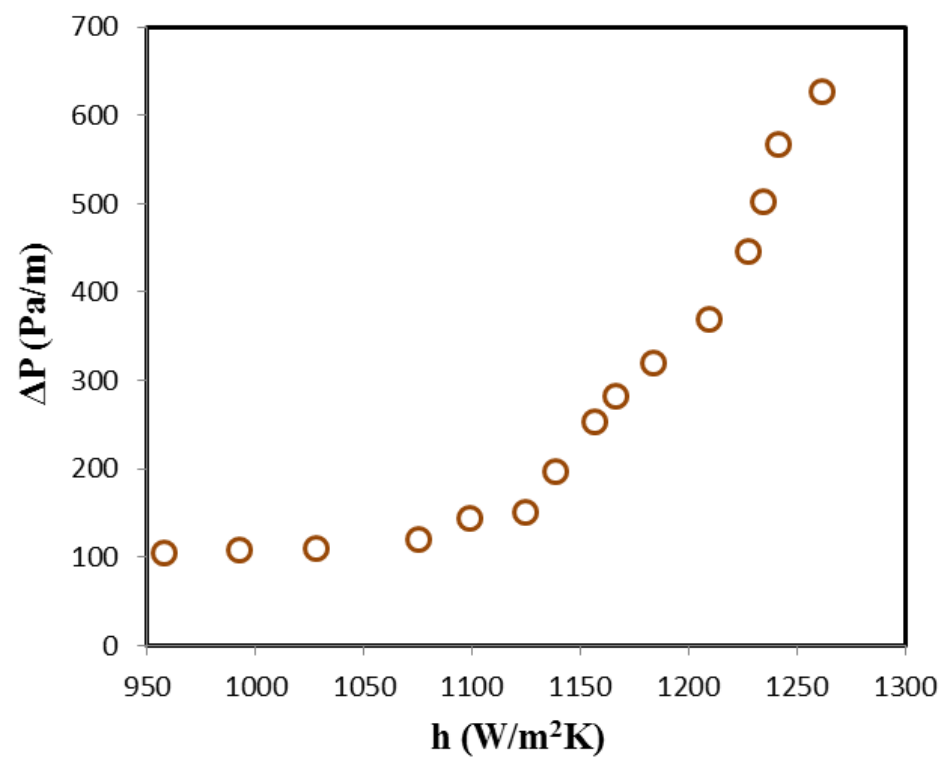

Fig. 11. Pareto diagram obtained from the two-objective optimization. 
Table 1. Specifications of the heat exchanger under study

\begin{tabular}{ccc}
\hline Specification & & Quantity \\
\cline { 1 - 1 } shell diameter & & $211 \mathrm{~mm}$ \\
tube diameter & & $19 \mathrm{~mm}$ \\
tube pitch & & $25 \mathrm{~mm}$ \\
number of tubes & & 37 \\
arrangement pattern of tubes & & $45^{\circ}$ triangular \\
thickness of baffles & & $3 \mathrm{~mm}$ \\
\hline
\end{tabular}


Table 2. The properties of $\mathrm{Al}_{2} \mathrm{O}_{3}$ nanoparticles and base fluid (pure water).

\begin{tabular}{ccccc}
\hline Property & & $\mathrm{Al}_{2} \mathrm{O}_{3}$ nanoparticles & & Pure water \\
\cline { 5 - 5 } \cline { 5 - 5 } Density $\left(\mathrm{kg} / \mathrm{m}^{3}\right)$ & & & 3970 & \\
Specific heat $(\mathrm{J} / \mathrm{kg} . \mathrm{K})$ & & 765 & & 4179 \\
Thermal conductivity $(\mathrm{W} / \mathrm{m} . \mathrm{K})$ & & 40 & & 0.613 \\
Dynamic viscosity $(\mathrm{kg} / \mathrm{m} . \mathrm{s})$ & & - & & $8.91 \times 10^{-4}$ \\
\hline
\end{tabular}




\section{Table 3}

Comparison between the results of current study with those reported by Zhang et al. [39]

\begin{tabular}{|c|c|c|c|c|c|c|}
\hline & \multicolumn{3}{|c|}{$h\left(\mathrm{~W} / \mathrm{m}^{2} \mathrm{~K}\right)$} & \multicolumn{3}{|c|}{$\Delta P(\mathrm{~Pa})$} \\
\hline & $\begin{array}{c}\text { Present } \\
\text { study }\end{array}$ & $\begin{array}{l}\text { Zhang et al. } \\
\text { [39] }\end{array}$ & $\begin{array}{l}\text { Error } \\
(\%)\end{array}$ & $\begin{array}{c}\text { Present } \\
\text { study }\end{array}$ & $\begin{array}{l}\text { Zhang et al. } \\
\text { [39] }\end{array}$ & $\begin{array}{c}\text { Error } \\
(\%)\end{array}$ \\
\hline$\beta=30^{\circ}$ & 317.8 & 328.2 & 3.15 & 199.8 & 195.6 & 2.17 \\
\hline$\beta=50^{\circ}$ & 228.2 & 220.5 & 3.51 & 113.0 & 116.7 & 3.18 \\
\hline
\end{tabular}




\section{Table 4}

Optimal cases obtained from genetic algorithm.

\begin{tabular}{|c|c|c|c|c|c|}
\hline \multirow[b]{2}{*}{ No. } & \multicolumn{3}{|c|}{ Input variables } & \multicolumn{2}{|c|}{ Outputs } \\
\hline & $\varphi(\%)$ & $\beta$ & $S$ & $h\left(\mathrm{~W} / \mathrm{m}^{2} \mathrm{~K}\right)$ & $\Delta P(\mathrm{~Pa} / \mathrm{m})$ \\
\hline 1 & 1.02 & 49.5 & 0.008 & 957.2 & 105.8 \\
\hline 2 & 1.19 & 30.0 & 0.596 & 1261.1 & 627.7 \\
\hline 3 & 4.62 & 33.1 & 0.127 & 1183.3 & 320.9 \\
\hline 4 & 4.52 & 30.1 & 0.508 & 1240.8 & 568.7 \\
\hline 5 & 4.85 & 37.9 & 0.207 & 1156.4 & 254.4 \\
\hline 6 & 4.72 & 35.7 & 0.161 & 1165.7 & 283.6 \\
\hline 7 & 4.60 & 30.7 & 0.124 & 1208.8 & 370.3 \\
\hline 8 & 4.49 & 45.0 & 0.290 & 1124.1 & 151.8 \\
\hline 9 & 2.52 & 49.5 & 0.008 & 1027.8 & 109.9 \\
\hline 10 & 4.43 & 38.7 & 0.047 & 1138.5 & 197.3 \\
\hline 11 & 3.57 & 47.8 & 0.024 & 1075.1 & 120.5 \\
\hline 12 & 3.50 & 44.8 & 0.096 & 1098.5 & 145.5 \\
\hline 13 & 1.77 & 49.7 & 0.017 & 992.0 & 108.1 \\
\hline 14 & 4.72 & 30.1 & 0.368 & 1234.0 & 503.8 \\
\hline 15 & 4.82 & 30.2 & 0.239 & 1227.3 & 447.1 \\
\hline
\end{tabular}




\section{Table 5}

Optimal cases obtained from genetic algorithm coupled with compromise programming technique.

\begin{tabular}{|c|c|c|c|c|c|c|c|}
\hline \multirow[b]{2}{*}{ No. } & \multicolumn{2}{|c|}{ Relative importance } & \multicolumn{3}{|c|}{ Input variables } & \multicolumn{2}{|c|}{ Outputs } \\
\hline & $\alpha_{1}$ & $\alpha_{2}$ & $\varphi(\%)$ & $\beta$ & $S$ & $h\left(\mathrm{~W} / \mathrm{m}^{2} \mathrm{~K}\right)$ & $\Delta P(\mathrm{~Pa} / \mathrm{m})$ \\
\hline 1 & 0 & 1 & 1.01 & 49.9 & 0.005 & 970.1 & 105.2 \\
\hline 2 & 0.1 & 0.9 & 5.00 & 46.2 & 0.075 & 1129.7 & 145.1 \\
\hline 3 & 0.2 & 0.8 & 4.99 & 44.8 & 0.067 & 1137.9 & 157.4 \\
\hline 4 & 0.3 & 0.7 & 4.99 & 43.9 & 0.074 & 1141.8 & 166.2 \\
\hline 5 & 0.4 & 0.6 & 4.99 & 42.8 & 0.061 & 1145.5 & 176.9 \\
\hline 6 & 0.5 & 0.5 & 5.00 & 33.3 & 0.032 & 1179.5 & 254.9 \\
\hline 7 & 0.6 & 0.4 & 4.99 & 31.2 & 0.001 & 1199.9 & 289.7 \\
\hline 8 & 0.7 & 0.3 & 4.99 & 30.6 & 0.001 & 1206.8 & 300.9 \\
\hline 9 & 0.8 & 0.2 & 4.99 & 30.0 & 0.010 & 1214.1 & 312.7 \\
\hline 10 & 0.9 & 0.1 & 4.99 & 30.0 & 0.036 & 1219.1 & 338.2 \\
\hline 11 & 1 & 0 & 4.99 & 30.0 & 0.599 & 1265.9 & 635.1 \\
\hline
\end{tabular}

